\title{
Spatial strategies: an attempt to classify daily movements of wild boar
}

\author{
François SPITZ and Georges JANEAU
}

Spitz F. and Janeau G. 1990. Spatial strategies: an attempt to classify daily movements of wild boar. Acta theriol. 35: 129-149.

Movement and activity of free-roaming wild boar were studied in a hunted forest area Thirty-six 24-h radio-tracking sessions were conducted on 2 sets: 5 subadult males (26 sessions) and 4 breeding females ( 10 sessions). Three kinds of movement were distinguished: activity zone (AZ), slow movement $(<1 \mathrm{~km} / \mathrm{h})$, fast movement $(>1 \mathrm{~km} / \mathrm{h})$. Individuals from both sets proved capable of performing all their nocturnal activity within a single AZ Another strategy, observed only in males, consisted of ranging continuously and not using $\mathrm{AZ}$. In most instances the night began with slow activity and an $\mathrm{AZ}$ was frequently associated with the initial resting place. Conversely, the final resting place is rarely associated with an AZ. The strategy employed led to a more or less complicated succession of the 3 kinds of movement. Total distance covered and activity duration were correlated with this complexity, but in any way most variations in the movement parameters are refered to individual, sex and period differences. If we assume that the home range organization is based on preferred places (AZ and resting places), a decision tree can be drawn. All results suggest that the succession of decisions was for the most part determined by the search for a maximum safety resting place. They also suggest that the use of $A Z$ is partly related to non-feeding activities, e.g. social relations and short resting phases. The wild boar movement strategy as a whole showed similarities with that used by a number of polyphagous predators.

INRA/IRGM, BP 27, 31326 Castanet Cedex, France

Key word: movements, behaviour, Sus scrofa

\section{Introduction}

Wild boar Sus scrofa Linnaeus, 1758 have long been labelled as "nomadic", "wandering" or "migrating" and are therefore a tempting material for movement studies. Moreover, this species is generally biphasic with a nocturnal active phase (Mauget 1984) which greatly simplifies the interpretation of radiotracking results. Long movements within the home range (Janeau and Spitz 1984), seasonal changes in home range location (Singer et al. 1981), long distance dispersion of subadults (Spitz et al. 1984), and even long distance wandering of a mother with piglets (Baettig 1980) have been observed. In a review, Dietrich (1984) cited very distant dispersal of tagged animals recorded in East Germany and Poland (males up to $300 \mathrm{~km}$, females up to 100 $\mathrm{km})$. Such movements are difficult to monitor except with the newly developped satellite tracking technics. Nevertheless, any great change in location, whatever the distance, is the result of a sequence of daily movements. In another review Mauget et al. (1984) showed that the spatial behaviour of the wild boar is a complex mixture of faithfulness to restricted areas and wandering. As a rule females generally hold 
long-term small home ranges, while males are more erratic, at least in their subadiult stage.

Detailed observations by Gundlach (1968), describing the development of behaviour, point out a number of features that support the idea that feeding behaviour corresponds to very slow movements (rooting and digging behaviour) and even to going back and forth around a central place (the wild boar can pick up voluminous items, such as maize ears or a mammal corpse, which are carried to a quiet place ffor eating). However, other activities can lead to the same movement pattern, for instamce wallowing and tree rubbing. Occasional fast back-and-forth movements duriing feeding activity, as well as travelling across open areas, or escaping after a disturbancce, are all performed at a speed exceeding $2 \mathrm{~km} / \mathrm{h}$ (F. Spitz, unpubl.). We can sum it up) as follows: movements slower than $1 \mathrm{~km} / \mathrm{h}$ generally correspond to feeding, exploring, wallowing and marking, and movements faster than $2 \mathrm{~km} / \mathrm{h}$ can be interpreted as connecting movements, excursions and escaping. Mauget $(1979,1980)$ propossed classifying the observed movement according to their geometrical pattern and speed.. In addition to slow and fast movement, he used the term 'zone activity' to describe goiing back and forth within a restricted area, which he termed 'activity zone'.

In the present paper, we try to analyze and classify the movements performed by radio-equipped wild boars during single nights as a means of better understanding such travelling behaviour.

A relatively long "methods" chapter will be devoted to a clear definition of the material facts and the parameters used in the movement analysis. Variability in results will be tested principally by comparing two sets of individuals (subadult males and breeding females).

\section{Materials and methods}

Study area

Grésigne (ca $44^{\circ} \mathrm{N}$ and $1^{\circ} 45^{\prime} \mathrm{W}$ ) is a forested area located on the southwestern border of Maassif Central in the south of France, with a Mediterranean-Atlantic climate. Altitudes ranged from 100 to 500 $\mathrm{m}$ a.s.l. Half of the area devoted to the study of wild boar populations was covered with deciduous oak forrest and chestnut copses, the rest with pastures, old fields and a few crops and vineyards. At least $20 \%$ of $f$ the area consisted of very favourable habitats for wild boar resting places (Janeau and Spitz 19984). Radiotracking operations extended over more than $200 \mathrm{~km}^{2}$.

\section{Animals}

The Grésigne wild boar population was studied from 1978 to 1982 (Spitz et al. 1984). Live trapping r was done with traps allowing simultaneous capture of up to 6 individuals ("cage" traps) or mote thann 10 ("corral" traps). A total of 86 individuals were caught in 1978 (8), 1979 (29), 1980 (38) and 1981 (11)), in a network of 12 traps extending over 3,500 hectares. The species is intensively hunted from October to eearly January, generally by small hunting teams with hounds. Mating occurs principally during the shooting season and farrowing takes place from February to August, with a peak in April-May (Spitz 1984, Pépiin et al. 1987). Hunters seldom kill animals weighing less than $15 \mathrm{~kg}$ (G. Valet, unpub.). The average dennsity before the shooting season, for the hunted part of the population, was estimated at about 2.5 per 100 hecttares 
(Spittz et al. 1984), i.e. about 90 individuals for the trapped area. About $40 \%$ were shot, so that the total population of adults and subadults after hunting was about 55 individuals. According to the known structure in the shot sample (Pépin et al. 1987) a tentative picture of the "normal" population present in our study area beforre farrowing would be: 25 females, including 8 to 12 breeding adults, and 30 males, including 5 to 10 adultts.

Only individualis weighing more than $38 \mathrm{~kg}$ were radio-equipped, i.e. only adult females, and subadult or acdult males. The characteristics of the radio-equipped animals are listed in Table 1. Nine animals were studiied during 24-hour sessions and are considered in the present study. All 4 females were breeding.

Table 1. Characteristics of the radio-equipped animals

\begin{tabular}{ccccc}
\hline Name & Age at capture & Breeding (fem.) & RT begin & RT end \\
\hline M05 & subadult & & Nov. 79 & July 81 \\
M06 & subadult & & March 81 & May 81 \\
M07 & subadult & & March 81 & April 81 \\
M08 & subadult & & March 81 & May 81 \\
M09 & subadult & & March 81 & April 81 \\
F01 & adult & 20 days a.f. & Sept. 79 & Oct. 79 \\
F02 & adult & 2 months a.f. & Sept. 80 & Sept. 80 \\
F03 & adult & 2 months b.f. & July 80 & Oct. 80 \\
F04 & adult & 1 month a.f. & July 80 & Sept. 80 \\
\hline
\end{tabular}

Population distribution and home range studies (Spitz and Janeau 1988) showed that the females belomg to three different breeding groups concentrated in the central part of the study area. The 6 subadult maless radio-equipped in 1981 (including the 4 dealt with in the present study) lived in larger home ranges. Thesce overlapped, creating a common part which was located within the 1980 breeding female home ranges. Thesee males belong to 2 or 3 family groups born in February and April 1980. In addition to the 1980 breedling females and the 1981 subadult males, we monitored from November 1979 to February 1981 a male born in early 1979, and we obtained 2 radiotracking sessions of a 1979 breeding female.

The movement and activity study described hereafter deals with 2 main sets of individuals: breedling females in summer-autumn (4 individuals and 10 radiotracking sessions) and subadult maless in spring ( 4 individuals and 8 sessions), plus one male followed from the subadult to the adult stage (18 scessions). In order to avoid direct disturbance by hunting, all radiotracking sessions were conducted at least 36 hours after a hunting day.

\section{Radiotracking}

Animals were equipped with AVM SB2 type radio-transmitters in collars with a total weight of c. $8060 \mathrm{~g}$. Potential battery life was about 2 years but most animals were checked for 2-3 months, only one fior more than 18 months.

Radiotracking operations were conducted with 2 vehicles equipped with a null-peak system and AVM LA12. receivers. Radio fixes were recorded simultaneously in both vehicles (synchronized by VHF transcceivers) generally with an interval of 15 to $20 \mathrm{~min}$ for each animal, up to a maximum of 30 minutes. Bearings were estimated by reference to the bearing of radio beacons placed at known locations (Janeau and Spitz 1984). Sessions started with the first movement following the location of the animal at its daytime restinig site, and ended after the animal had been confirmed to settle in its next resting place.

The number of fixes per session depended on the length of the activity phase and the interval between fixes. The location accuracy of a fix depended on the angular error in each receiving station and on the distamce from receiving antenna to animal (Heezen and Tester 1967). In Grésigne, our mobile stations were usually 1 to $2 \mathrm{~km}$ from the animal, and the angular error usually small (about \pm 1 ). For these conditions, the area $0 \mathrm{f}$ uncertainty for each fix was smaller than $50 \times 50 \mathrm{~m}$, that was verified by a number of experimental 
localizations of "lost" transmitters, and the discovery of farrowing nests after radio-localization. In fact, we have considered that location points cannot be distinguished accurately when they are separated by less than $50 \mathrm{~m}$. Consequently, individualizing more or less parallel segments of an animal's path which were less than $50 \mathrm{~m}$ apart was considered unrealistic.

\section{Description of the daily movement}

Basic statements: During a radiotracking session, the nocturnal movement of the wild boar are recorded in terms of points. We assume that the actual walk was represented by the successive segments joining the successive points. We calculated the average speed as the quotient of a segment length by the time elapsed. We identified an "activity zone" when a number of segments (at least 2) went here and there within a small area (less than 25 hectares) for a duration of at least 1 hour. Zone activity was delimited in space on the movement map, and in time by its first and last recorded point. To simplify the classification of movements we only considered a limit at $1 \mathrm{~km} / \mathrm{h}$ separating "slow" or "possibly feeding" from "fast" or "certainly not feeding". We identified slow or fast segments outside activity zones only.

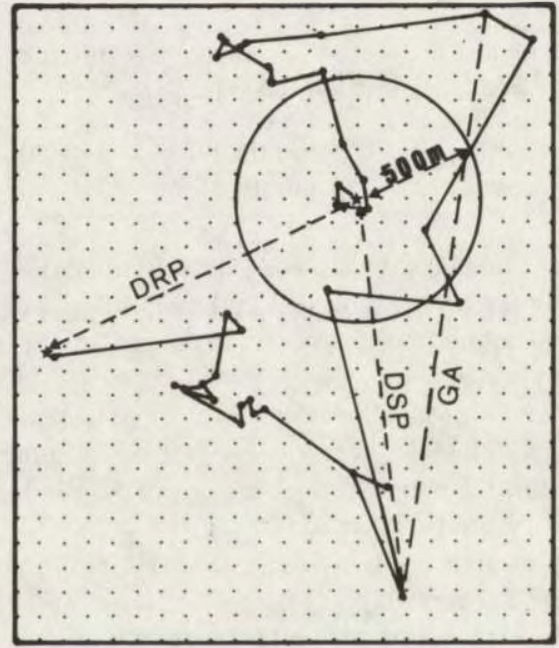

Fig. 1. Schematic map of a radiotraching session. The scale is given by the grid (points $100 \mathrm{~m}$ apart) and the $500 \mathrm{~m}$-radius circle.

Measurements (Fig. 1):

Total distance travelled (TDT) - this parameter was estimated as minimal by adding all segments from fix to fix (Mauget and Sempéré 1978, Janeau and Spitz 1984). We know, after Tester and Siniff (1965) that this distance is only an underestimate of the actual distance covered.

Average radius (AVR) - this is the mean of the distances of fixes to the apparent center of activity (Calhoun and Casby 1958).

Distance between resting places (DRP) - this is the straight-line distance from the initial resting place to the next one.

Great axis $(\mathrm{GA})$ - this is the straight-line distance between the 2 most distant fixes.

Total activity duration (AD), time spent in activity zones (ZD), time spent in slow movements (SLD), time spent in fast movements (FD), do not need comments.

Slow activity duration (SA) is the total of ZD and SLD.

General pattern - a study of the daily movement pattern through multivariate analysis appeared very deceiving when using the above-cited parameters. They can reveal the extent and some distributional 
traits of the daily range but not its design. In the absence of any adapted shape-analysis software, we have followed the visual classification proposed in Spitz (1989): movements observed in the present work were classified by comparison with the typical patterns represented in Fig. 2.

Time profiles: variation in the course of the night was analyzed for speed and distance from the starting point.

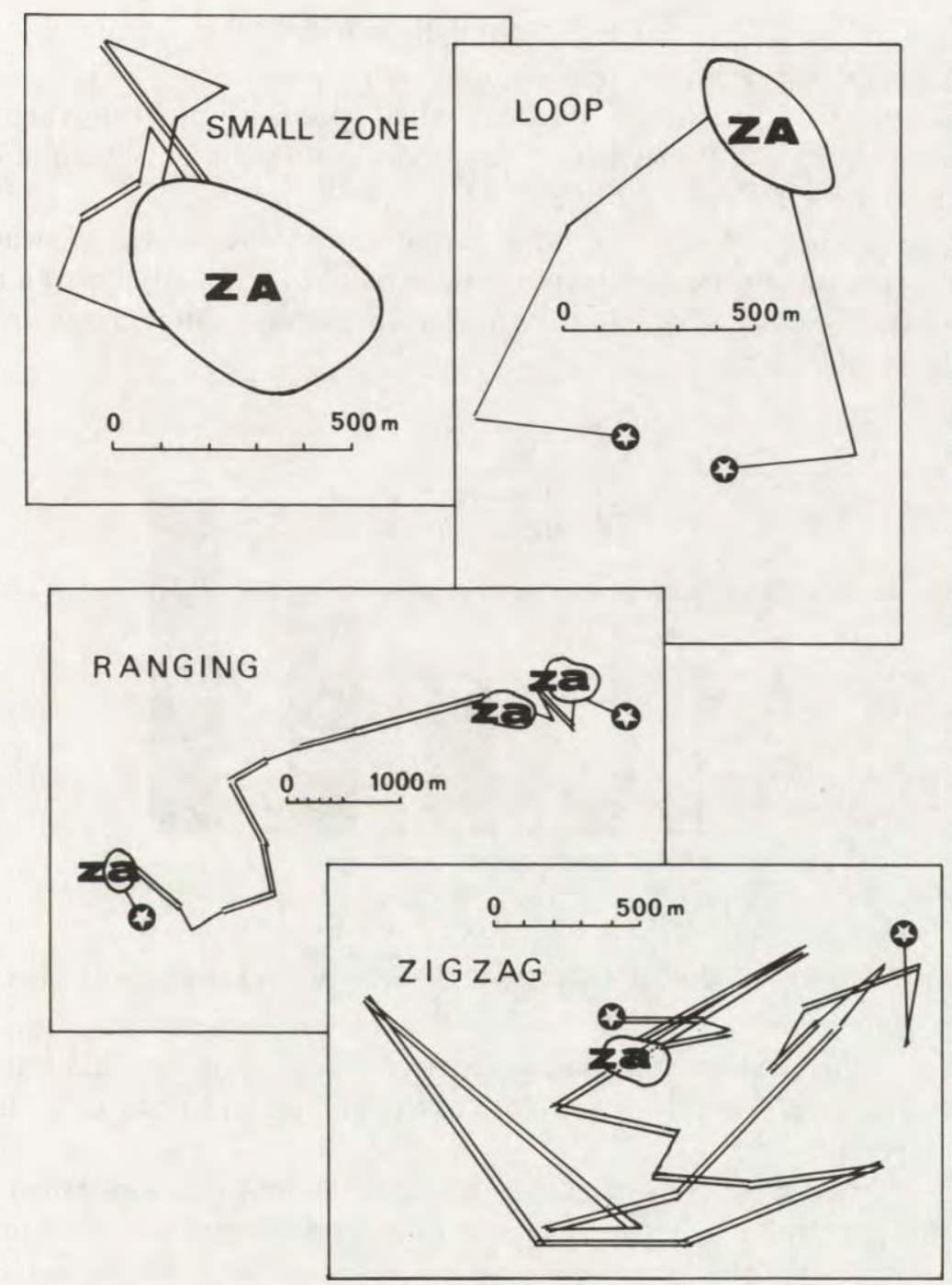

Fig. 2. Models of the 4 typical movement patterns according to Spitz (1989). ZA =activity zone. Double lines $=$ fast movement. Simple lines $=$ slow movement.

\section{Statistical methods}

Averages were compared by the $t$-test. Tendencies were analyzed by simple regression. Cross-tables were submitted to the chi-square test $\left(\chi^{2}\right.$-test). Non-linear regression was used to detect seasonal tendencies. 
The respective influence of various factors on parameters of the daily range was assessed by a segmentation programme (STATITCF software library, ITCF, France). This programme belongs to the group of Automatic Interaction Detection techniques (Morgan and Sonquist 1963).

\section{Results}

\section{General pattern of the movement}

Four principal patterns have been observed:

(1) Small zone (8 occurrences) - the individual spends all night moving within the same activity zone, sometimes with a few short excursions outside, and/or a short movement to a distant resting place.

(2) Ranging (9 occurrences) - during its movement, the animal is steadily going farther from the starting point (except within activity zones, if any), even if not always straight away. The great axis of the total movement does not differ greatly from the line joining the resting places.

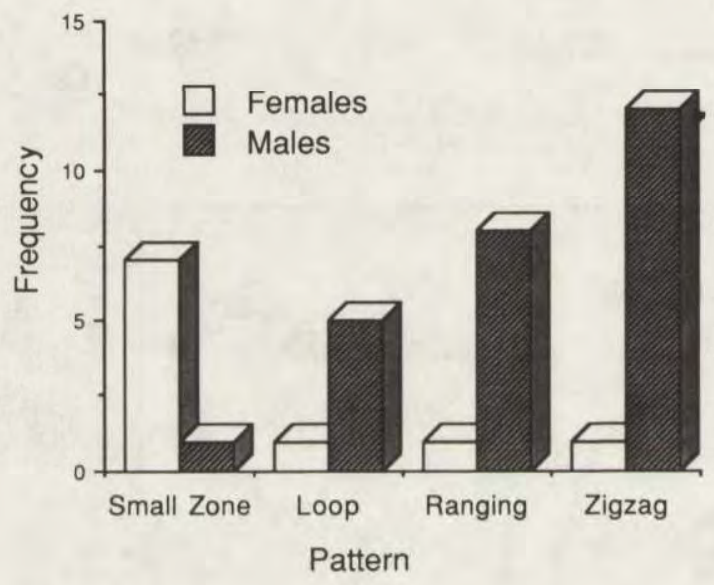

Fig. 3. Distribution of the 4 movement patterns in male and female wild boars.

(3) Loop (6 occurrences) - the wild boar follows a more or less elliptical route, the second resting place being relatively close to the first one. In practice we limited this distance to $800 \mathrm{~m}$.

(4) Zigzag (13 occurrences) - zigzag is a rather complicated movement with long straight walks separated by great changes in heading. Contrary to the ranging pattern, the great axis of the total movement may be quite distinct from the line joining the resting places.

All patterns have been observed in both sexes. "Small zone" is largely dominant in breeding females. In males "zigzag" is the dominant pattern while "small zone" is the rarest (Fig. 3). No definite change with time or age is noticeable along the 18 sessions for male no. 10. Patterns other than "small zone" appear in breeding females as soon as 25 days after farrowing (Table 2). 
Table 2. Movement parameters for each RT session. Individuals are named by $\mathrm{M}$ for males and $\mathrm{F}$ for females with number. DAF: days after farrowing. NBZ: number of activity zones. All other abbrevations see text.

\begin{tabular}{|c|c|c|c|c|c|c|c|c|c|c|c|}
\hline Name & Date & DAF & TDT & AVR & DRP & GA & $\mathrm{AD}$ & ZD & SLD & FD & NBZ \\
\hline M05 & $4 / 12 / 79$ & & 7800 & 1010 & 1960 & 3500 & 960 & 390 & 465 & 105 & 2 \\
\hline M05 & $8 / 1 / 80$ & & 3000 & 330 & 1590 & 1600 & 923 & 150 & 705 & 68 & 1 \\
\hline M05 & $30 / 1 / 80$ & & 13290 & 1000 & 1890 & 4700 & 928 & 150 & 365 & 413 & 1 \\
\hline M05 & $14 / 2 / 80$ & & 7540 & 920 & 1350 & 3500 & 865 & 270 & 515 & 80 & 1 \\
\hline M05 & $26 / 2 / 80$ & & 12500 & 800 & 2150 & 4000 & 950 & 420 & 295 & 235 & 2 \\
\hline M05 & $11 / 3 / 80$ & & 9200 & 1550 & 4350 & 4600 & 870 & 570 & 60 & 240 & 3 \\
\hline M05 & $25 / 3 / 80$ & & 7400 & 540 & 1070 & 1700 & 865 & 705 & 55 & 105 & 2 \\
\hline M05 & $15 / 4 / 80$ & & 10010 & 480 & 1670 & 1800 & 833 & 668 & 15 & 150 & 2 \\
\hline M05 & $29 / 4 / 80$ & & 6930 & 510 & 2360 & 3800 & 840 & 675 & 30 & 135 & 2 \\
\hline M05 & $8 / 7 / 80$ & & 3820 & 450 & 460 & 1100 & 645 & 165 & 440 & 40 & 1 \\
\hline M05 & $17 / 7 / 80$ & & 8440 & 1240 & 3170 & 3800 & 752 & 0 & 452 & 300 & 0 \\
\hline M05 & $23 / 7 / 80$ & & 4920 & 710 & 740 & 2500 & 554 & 0 & 314 & 240 & 0 \\
\hline M05 & $7 / 10 / 80$ & & 5390 & 1220 & 4330 & 4600 & 704 & 0 & 554 & 150 & 0 \\
\hline M05 & $4 / 11 / 80$ & & 8500 & 900 & 3080 & 3300 & 690 & 270 & 290 & 130 & 2 \\
\hline M05 & $25 / 11 / 80$ & & 5660 & 370 & 60 & 1700 & 630 & 340 & 270 & 20 & 1 \\
\hline M05 & $16 / 12 / 80$ & & 5250 & 610 & 1500 & 2300 & 675 & 0 & 565 & 110 & 0 \\
\hline M05 & $20 / 1 / 81$ & & 6650 & 640 & 1480 & 2000 & 630 & 0 & 360 & 270 & 0 \\
\hline M05 & $10 / 2 / 81$ & & 3820 & 540 & 770 & 2000 & 570 & 0 & 510 & 60 & 0 \\
\hline M06 & $12 / 5 / 81$ & & 2610 & 160 & 300 & 700 & 410 & 410 & 0 & 0 & 1 \\
\hline M07 & $7 / 4 / 81$ & & 11510 & 640 & 1070 & 3600 & 541 & 135 & 171 & 235 & 2 \\
\hline M07 & $28 / 4 / 81$ & & 10690 & 440 & 970 & 2000 & 600 & 210 & 145 & 245 & 1 \\
\hline M08 & $24 / 3 / 81$ & & 3940 & 220 & 670 & 1000 & 538 & 230 & 280 & 28 & 1 \\
\hline M08 & $7 / 4 / 81$ & & 12660 & 640 & 3650 & 3800 & 523 & 80 & 70 & 373 & 1 \\
\hline M08 & $12 / 5 / 81$ & & 3420 & 480 & 240 & 1400 & 553 & 0 & 450 & 103 & 0 \\
\hline M09 & $24 / 3 / 81$ & & 3160 & 310 & 770 & 1100 & 285 & 0 & 220 & 65 & 0 \\
\hline M09 & $7 / 4 / 81$ & & 8660 & 430 & 1820 & 2200 & 590 & 210 & 160 & 220 & 1 \\
\hline F01 & $14 / 9 / 79$ & 25 & 3000 & 330 & 870 & 1000 & 718 & 660 & 0 & 58 & 2 \\
\hline F01 & $25 / 9 / 79$ & 36 & 4110 & 110 & 450 & 600 & 805 & 710 & 85 & 10 & 1 \\
\hline F02 & $9 / 9 / 80$ & 61 & 6630 & 210 & 440 & 1400 & 809 & 750 & 50 & 9 & 1 \\
\hline F02 & $23 / 9 / 80$ & 75 & 8080 & 320 & 80 & 1500 & 915 & 560 & 210 & 145 & 1 \\
\hline F03 & $9 / 980$ & -2 & 2100 & 110 & 150 & 600 & 673 & 673 & 0 & 0 & 1 \\
\hline F03 & $23 / 9 / 80$ & 12 & 3180 & 130 & 10 & 600 & 795 & 795 & 0 & 0 & 1 \\
\hline F03 & $7 / 10 / 80$ & 26 & 4440 & 180 & 840 & 1100 & 870 & 405 & 430 & 35 & 1 \\
\hline F03 & $21 / 10 / 80$ & 40 & 9210 & 720 & 1420 & 2500 & 810 & 300 & 355 & 155 & 2 \\
\hline F04 & $17 / 7 / 80$ & 45 & 6910 & 230 & 170 & 1000 & 660 & 375 & 185 & 100 & 1 \\
\hline F04 & $23 / 7 / 80$ & 51 & 2870 & 110 & 520 & 800 & 755 & 735 & 10 & 102 & 1 \\
\hline
\end{tabular}

\section{Distance and time parameters}

All results are discussed with regard to the segmentation process taking into account the respective effect of individual, sex, period and departure mode. Three periods were considered: October-January is characterized by hunting activities and a high production of acorn and chestnut. February - June is a non-hunting period with plenty of chestnut and grass but acorns have become rarer. July-September is also a non-hunting period with plenty of invertebrates, the development of various underground organs in plants and the onset of small fruit production. Departure modes (see hereafter) were: "stay some time in zone activity" or "slow movement" or 


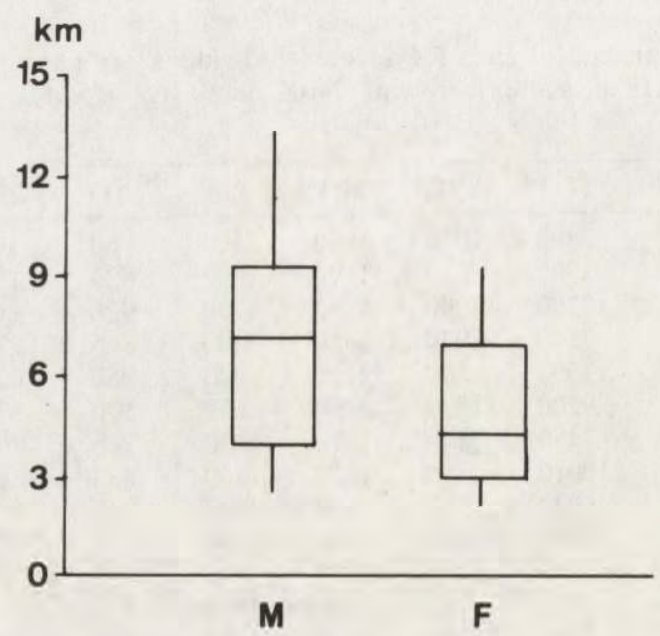

Fig. 4. Box-and-whisker plot of total distance travelled (TDT) in males (M) and females (F). The box contains $50 \%$ of the observed values. The horizontal line represents the median, perpendicular lines - SD.

"fast movement". All results cited without statistical test are issued from the segmentation process and have been accepted at the 0.05 probability level. When taking the "individual" factor into account, this factor is always responsible for the first segmentation. However it is noticeable that all females behave similarly (they are always found in the same segmentation group) except for TDT. Results hereafter do not take individual effect into account.

Total distance travelled: Period is the predominant factor, separating July-September (mean $=4914 \mathrm{~m}, \mathrm{n}=11, \mathrm{SD}=2131 \mathrm{~m}$ ) from the other periods (mean $=7329 \mathrm{~m}, \mathrm{n}=25, \mathrm{SD}=3190 \mathrm{~m}$ ). Global difference between males and females is moderate as illustrated in Fig. 4.

In male 05 the variation with age (or time) is shown in Fig. 5. A two-peak pattern is observable, with peaks separated by about 1 year, that is an indication of a seasonal cycle with shorter TDT in summer. For breeding females, the distance covered increases with time after farrowing $(r=0.677, F$-ratio $=7,1$ and 9 d.f., $p=0.03)$ but this could be a masked effect of season (Fig. 6). The largest distances are observed in the "zigzag" pattern (mean $=8351 \mathrm{~m}, \mathrm{SD}=3117 \mathrm{~m}$ ) and the "ranging" pattern $($ mean $=7351 \mathrm{~m}, \mathrm{SD}=3223 \mathrm{~m})$, the lowest in the "small zone" ( mean $=4561 \mathrm{~m}$, $\mathrm{SD}=2299 \mathrm{~m}$ ) and "loop" (mean $=4346 \mathrm{~m}, \mathrm{SD}=833 \mathrm{~m}$ ) patterns.

Average radius: Sex is the most differentiating factor, with longer AVR in males (mean $=659 \mathrm{~m}, \mathrm{SD}=331 \mathrm{~m})$ than in females $($ mean $=245 \mathrm{~m}, \mathrm{SD}=176 \mathrm{~m})$. Significant differences are also observed between the movement patterns: $944 \mathrm{~m}$ for "ranging" against $536 \mathrm{~m}$ for "zigzag" $(t=2.880, p=0.009)$ and $455 \mathrm{~m}$ for loop $(t=3.214$, $p=0.0067)$. The latter was significantly greater than "small-zone" (mean $=172 \mathrm{~m}$, $t=3.675, p=0.0032$ ).

Distance between resting places: The first discrimination was due to sex (average in males: $1672 \mathrm{~m}$, in females: $495 \mathrm{~m}, t=4.296, p=0.02)$. The definition of "small zone" 

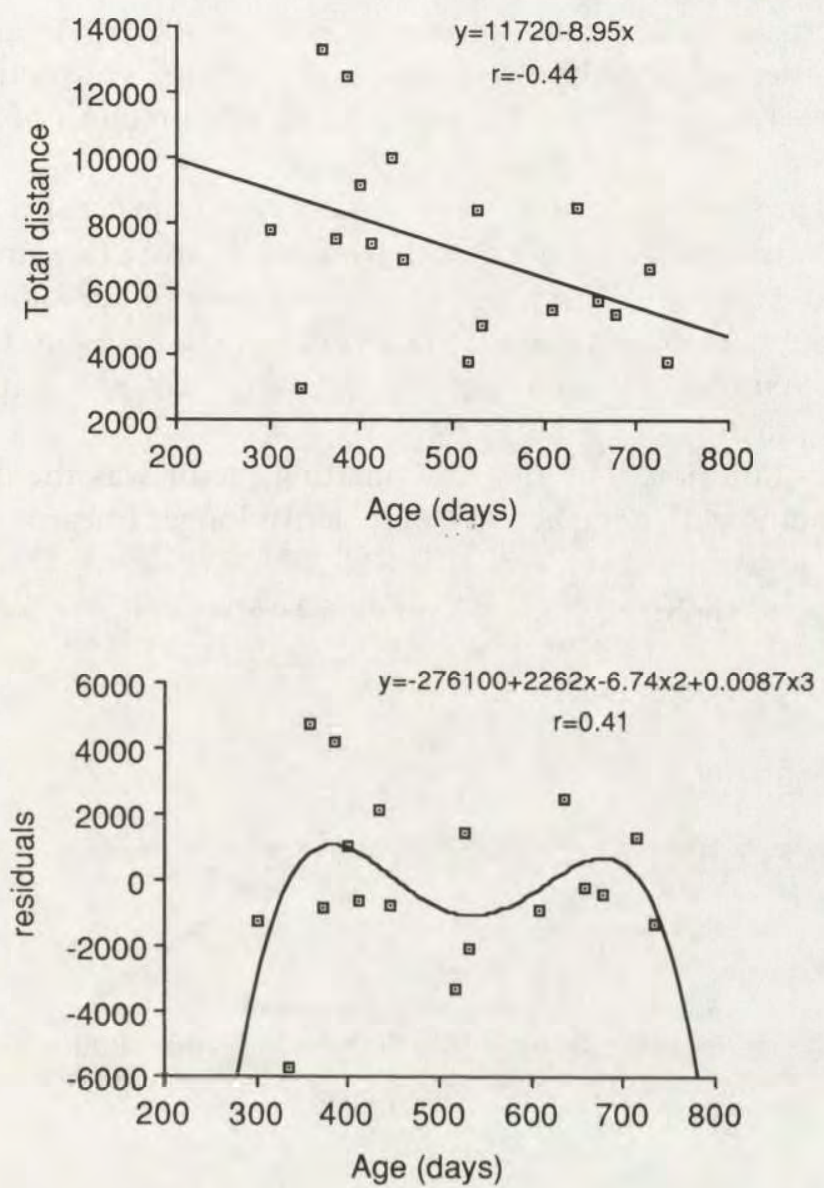

Fig. 5. Correlation of TDT and age for male 05. Top graph: absolute value of TDT. Bottom graph: variation with time of the unexplained part (residuals) of the model. Male 05 being capture in early November, the 2 peaks in bottom graph are approximately located in mid-winter.

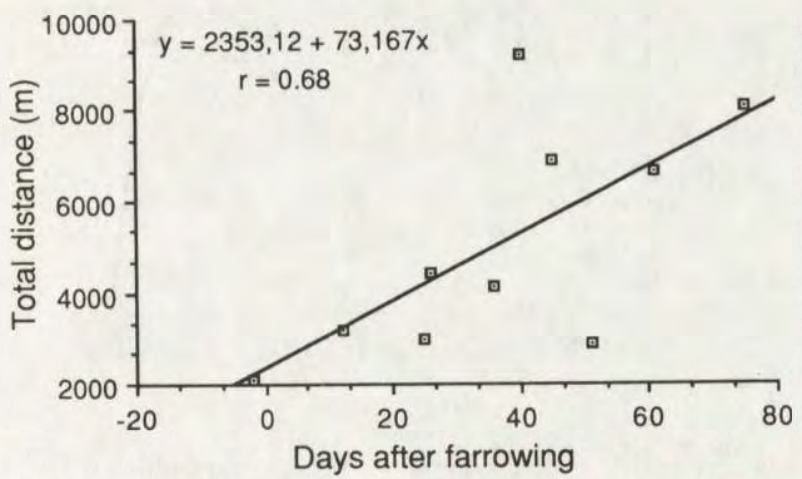

Fig. 6. Correlation of TDT and time with regard to farrowing date. 
and "loop" patterns include a limitation of this distance $(800 \mathrm{~m})$. An almost significant differençe was observed between "ranging" and "zigzag" (respective means 2,510 $\mathrm{m}$ and $1,584 \mathrm{~m}, t=1.928, p=0.06$ ). There was no significant effect of age or date after farrowing.

Great axis: The situation for this measurement was quite parallel to that observed for the distance between resting places. Both parameters are in fact strongly correlated $(r=0.832, F$-ratio $=77,1$ and 35 d.f., $p<0.005)$. Highest average values were noted in the "ranging" pattern $($ mean $=3400 \mathrm{~m}, \mathrm{SD}=1311 \mathrm{~m})$, the lowest in the "small zone" pattern (mean $=900 \mathrm{~m}, \mathrm{SD}=366 \mathrm{~m})$. "loop" and "zigzag" patterns were not significantly separated.

Total activity duration: The first discrimating factor was the departure mode. Individuals beginning with zone activity were active longer ( mean $=792 \mathrm{~min}, \mathrm{n}=17$,
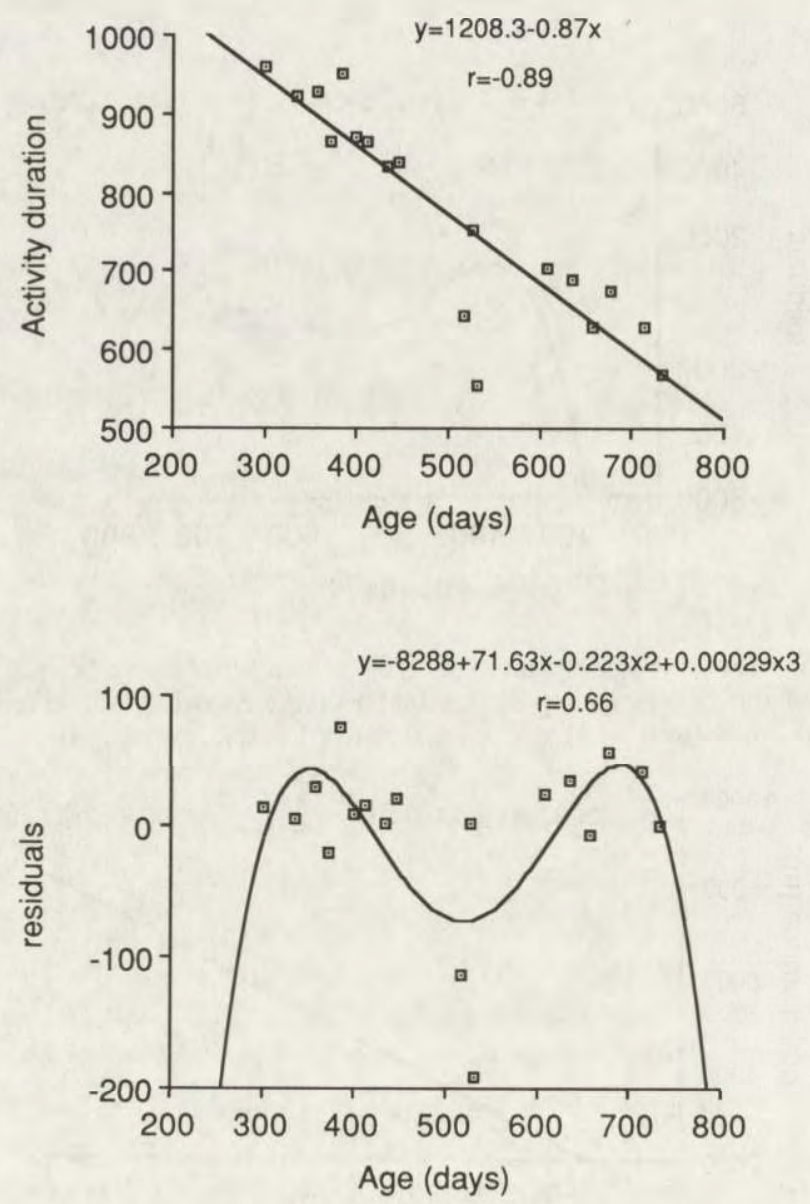

Fig. 7. Correlation of AD and age for male 05. Top and bottom graphs like in Fig. 5 . The 2 peaks in the residuals graph are separated by approximately one year and located in late December. 
$\mathrm{SD}=132 \mathrm{~min}$ ) than those moving away, slow or fast (mean $=645 \mathrm{~min}, \mathrm{n}=19, \mathrm{SD}=147$ $\mathrm{min})$. Within this second group, individuals observed during July-September and October - January were active longer (mean $=719 \mathrm{~min}, \mathrm{n}=10, \mathrm{SD}=112 \mathrm{~min}$ ) than those observed in the February-June period (mean $=562 \mathrm{~min}, \mathrm{n}=9, \mathrm{SD}=138 \mathrm{~min}$ ).

There was a global difference between females (mean $=781 \mathrm{~min}$ ) and males (mean $=689 \mathrm{~min}, t=4.6739, p=0.0394$ ). For movement patterns, significant differences appeared only between "ranging" and "zigzag" ( $823 \mathrm{~min}$ against $667 \mathrm{~min}, t=2.495$, $p=0.0205$ ), and between "ranging" and "loop" ( $823 \mathrm{~min}$ against $637 \mathrm{~min}, t=3.062$, $p=0.0067$ ). The variation along age (or time) for male 05 is presented in Fig. 7 . A non-linear regression shows a two-peak pattern, like in TDT, with an inter-peak interval of about 1 year. This agrees with the period effect noted with the segmentation programme.

Time spent in activity zones: Females spent significantly more time than males in zone activity (average values $596 \mathrm{~min}$ and $232 \mathrm{~min}, t=5.077, p<0.001$ ). Values observed in the "small-zone" pattern were greater than in the three other patterns (626 min against respectively $279 \mathrm{~min}$ for "zigzag", with $t=3.775$ and $p=0.0013,273 \mathrm{~min}$ for "ranging" and 151 min for "loop").

Time spent in slow movement: The first differentiating variable was the departure mode. Individuals beginning with zone activity spent much less time in slow movement (mean $=160 \mathrm{~min}, \mathrm{n}=17, \mathrm{SD}=197 \mathrm{~min}$ ) than those moving away (mean $=334 \mathrm{~min}$, $\mathrm{n}=19, \mathrm{SD}=155 \mathrm{~min}$ ). The global difference between females and males (respective means 132 and $298 \mathrm{~min}, t=2.628, p=0.0123$ ) was subordinated to this first segmentation. SLD observed in "small-zone" pattern (mean $=67 \mathrm{~min}$ ) was significantly shorter than in "zigzag" ( $m e a n=209 \mathrm{~min}, t=2.645, p=0.0153$ ). Significant differences also existed between "zigzag" and "loop" (209 min against $402 \mathrm{~min}, t=3.346$, $p=0.0038$ )

Time spent in fast movement: The first segmentation was due to sex. Females (mean $=52 \mathrm{~min}, \mathrm{SD}=57 \mathrm{~min}$ ) performed less fast movements than males (mean $=158$ min, $\mathrm{SD}=107 \mathrm{~min}$ ). Similarly, "small zone" pattern differed significantly from "zigzag" and "ranging" ( $34 \mathrm{~min}$ against 178 and $171 \mathrm{~min}, p<0.001$ ), but not from "loop".

\section{Time profiles}

Examples of speed curves are given at Fig. 8. Except for a few breeding females which stayed steadily at low speed, the curves are very irregular in shape with a low number of narrow peaks exceeding $2.5 \mathrm{~km} / \mathrm{h}$. Extreme values, above $10 \mathrm{~km} / \mathrm{h}$, were rarely observed and only for durations not greater than the fix interval (10 to $30 \mathrm{~min}$ ).

Distance curves (examples in Fig. 9) present characteristic patterns, obviously related to the general pattern of the movement. In the "stay in a small zone" pattern, the distance curve shows a number of movements from and to the starting point but within $500 \mathrm{~m}$ from this point. What we have called "short excursions outside the activity zone" generally appear as short peaks above $500 \mathrm{~m}$ in the distance curve. In the 


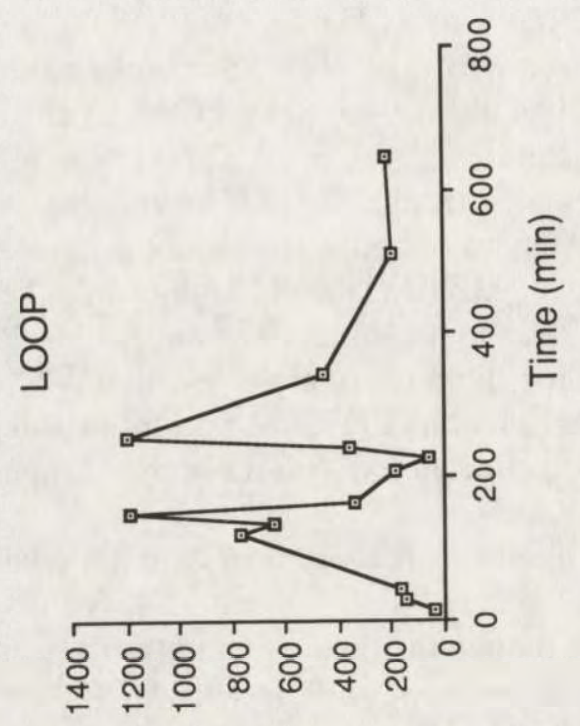

(4/u) pəəds

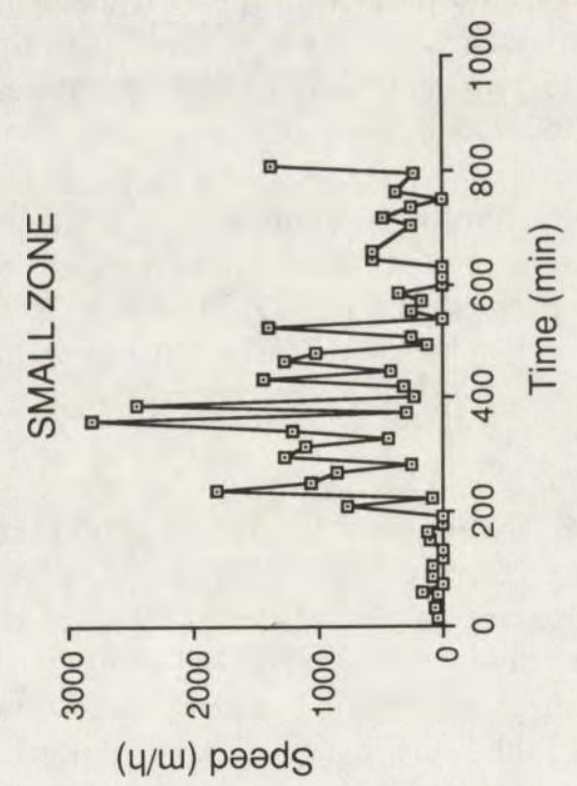

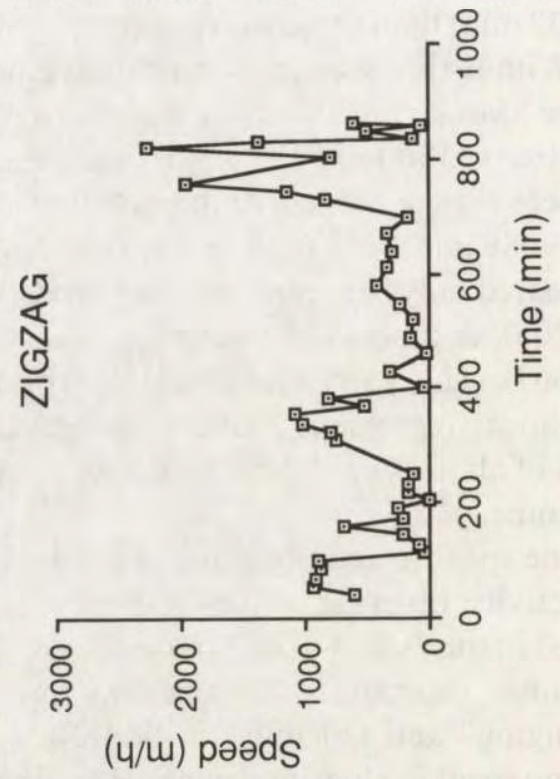

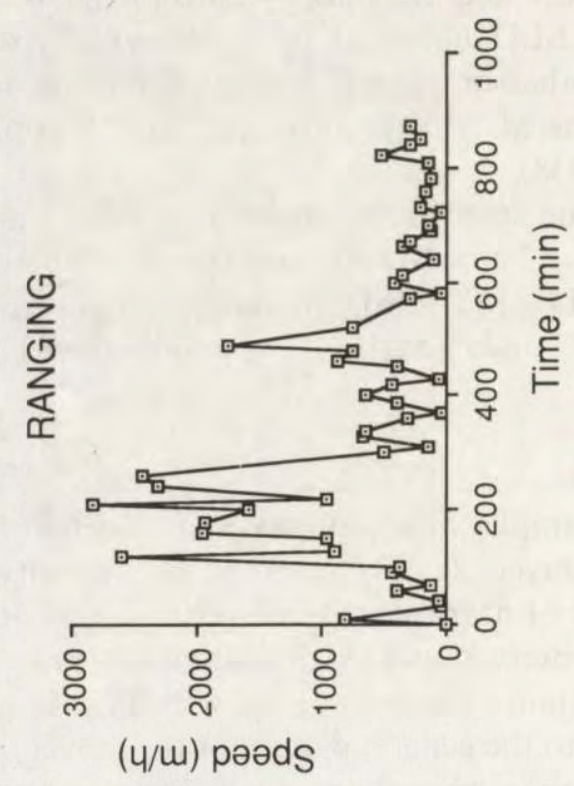




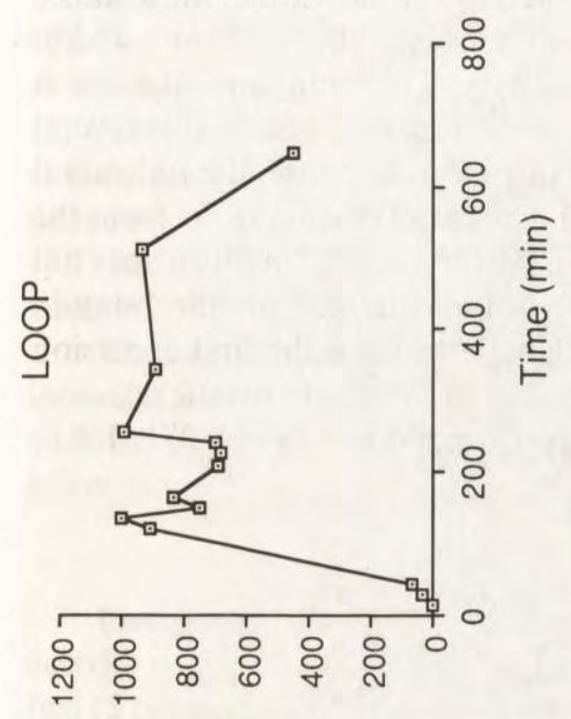

(w) әouełs!

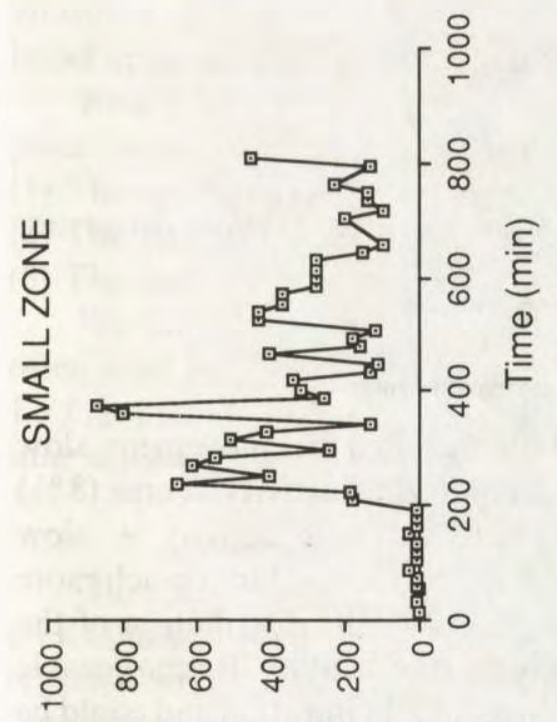

(u) әoueıs!ด

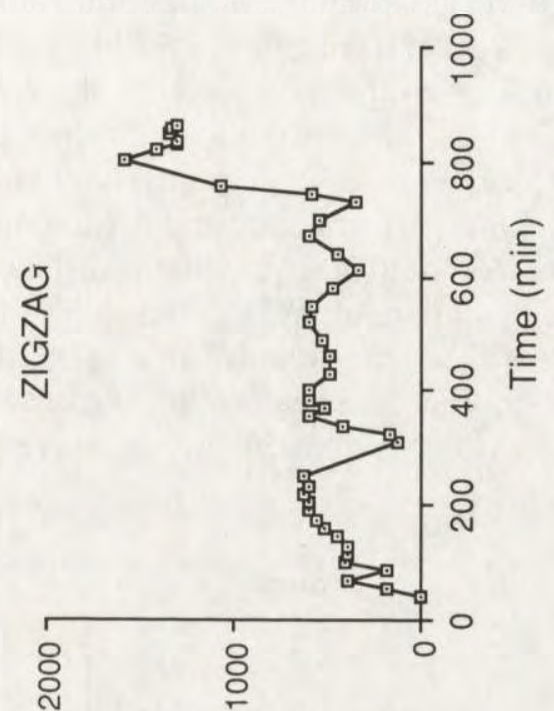

(w) әงuełs!ด

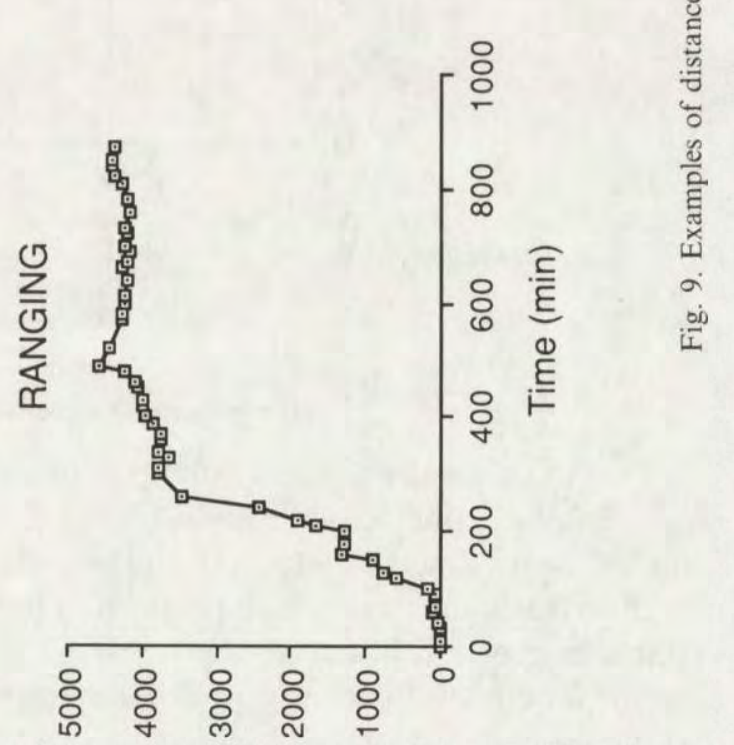

(w) әวuน!s!a 
"loop" pattern, whatever the shape of the route followed by the individual, the distance curve shows a general tendency of the individual to move away in the first hours, and to begin returning several hours before the end of activity. The "ranging" pattern is represented by characteristic curves in which the distance increased steadily for several hours up to values largely exceeding $1000 \mathrm{~m}$. After this increase phase, the individual may or may not perform back and forth movements, but always staying far from the initial point. As could be expected, the distance curve for the "zigzag" pattern does not show any regular trend. When considering the $500 \mathrm{~m}$ limit defined for the "stay in a small zone" pattern, we noted that in 19 of the 26 male sessions the first excursion beyond this limit occured before $200 \mathrm{~min}$ of activity, while in 8 of the 10 female sessions, the first excursion beyond $500 \mathrm{~m}$ was observed only after $200 \mathrm{~min}\left(\chi^{2}=8.371,1\right.$ d.f., $p<0.01)$.

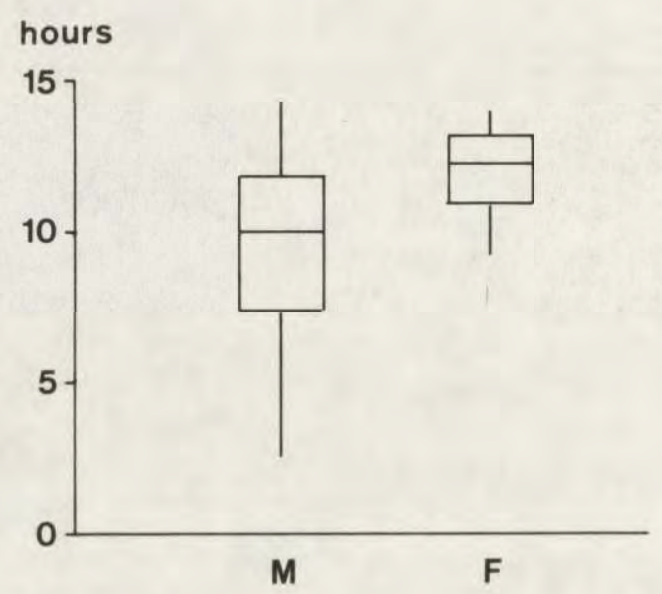

Fig. 10. Box-and-whisker plot of slow activity duration in males (M) and females (F). SD on the vertical scale in hours.

\section{Distribution and succession of movement types}

Two thirds of the radiotracking sessions ( 24 of 36 ) included fast movement, slow movement and zone activity. Eight $(22 \%)$ did not include zone activity. Three $(8 \%)$ included only zone activity. On the whole, slow activity (zone activity + slow movement) amounted to a high proportion in females ( 80 to $100 \%$ ), but a much more variable proportion in males ( 29 to $100 \%$ ). Figure 10 shows the distribution of the absolute time spent by males and females, respectively, in slow activity. It is noticeable that the slow activity of the observed males was very irregular in duration and could be as short as $2.5 \mathrm{~h}$. Conversely $90 \%$ of the observed female sessions were characterized by slow activity exceeding 10 hours $\left(\chi^{2}=4.862,1 d . f\right.$., $\left.p=0.02\right)$.

An analysis of the succession in time of the 3 movement types allows one to define 
3 different situations:

(1) The first one concerns individuals staying constantly in an activity zone (1 session for a male, 2 sessions for a female).

(2) Sessions including at least one activity zone, are observed 25 times. In this second set, we found 16 sessions where zone activity begins early (less than 1 hour after the onset of activity) and close to the starting point (less than $500 \mathrm{~m}$ apart).

(3) The third situation concerns sessions not including zone activity. These were observed 8 times, only for males. In 6 instances, activity begins with a slow phase.

The number of different activity zones occupied during the same night by an individual was introduced as one of the factor in another segmentation process. This variable appears as the first discriminant factor for TDT and AVR when individual effect is excluded.

\section{Movements from and to the resting place}

Leaving the resting place: There are three ways of entering the active phase: zone activity near the resting place ( 19 occurrences), getting away slowly ( 12 occurrences) or fast ( 5 occurrences). In other words, the main tendency was to stay close to the resting place for a while (that we found for 9 of 10 female sessions) or getting away slowly (strategy used only by males). Fast movement, when starting from the resting place, was less often used (only one instance by a breeding female).

An apparent age-related trend existed in male 05 . He used essentially "zone activity around resting place" until 15 months old, and "long slow route" afterwards. However, other males less than 15 months old did not use the first pattern at all. No trend appeared with time after farrowing.

Reaching the next resting place: Three distinct ways of reaching the next resting place were observed:

(1) The resting place may be occupied within the last activity zone ( 9 obs.)

(2) The resting place may be reached after a slow walk (20 obs.)

(3) The individual may stop at the end of a fast travel ( 7 obs.).

We observed that the solution "resting place in the last activity zone" was less often used by males ( 3 of 26 sessions) than by females ( 6 of 10 sessions) $\left(\chi^{2}=9.046\right.$, 1 d.f., $p<0.01)$. No trend can be distinguished with increasing age in male 05 nor with time after farrowing.

\section{Summary of the description and comments}

Our results show that two opposed basic strategies enable the wild boar to perform all its daily activity. The first basic strategy is "staying in the same zone" which is represented by the "small zone" movement pattern. The second basic strategy is "ranging only" which corresponds to the night activity during which zone activity is not used. Each of these basic strategies was observed 8 times, and together represented a little less than half of the radiotracking sessions. The 20 other sessions combined both basic strategies. 
Does one of the two basic movement strategies have priority over the other, i.e. is one of them used preferably except in the presence of some adverse constraint? We must consider separately the female sample and the male sample. For the females (which were all accompanied by piglets) it is clear that the "staying in zone" strategy was the main tendency as shown by 7 "small zone" patterns and 2 "zone near the initial resting place", i.e. $90 \%$ of the observed nocturnal activity. On the other hand, only 12 male sessions ( $46 \%$ ) began their activity in a zone (the "staying in zone" basic strategy was observed only once), and 14 began with another kind of movement, among which 8 finally did not perform activity zone at all (i.e. they used the "ranging only" basic strategy).

At the individual level all observed wild boars performed zone activity at least once, while only males 05 and 08 spent all night without zone activity. This indicates that "staying in zone" was the more general strategy for all wild boars.

When introduced as an explanatory variable, the number of activity zones used during one night was responsible for the first dichotomy of TDT and AVR. However, the dichotomy does not separate "no zone" from "one zone or more" but "zero or one" from "two or three". Consequently we cannot say that the use of one or the other basic strategy is of major importance in the distance or duration parameters of the daily range.

In conclusion we can say that the daily movement of the wild boars observed during this work can be interpreted through the hypothesis of two basic movement strategies, which can be used independently or in combination. The strict "staying in zone" strategy resulted in the "small zone" pattern, characterized by a reduced range of variation in the quantitative parameters except for the total time spent in activity. All other situations ("ranging only" use singly, or both strategies combined) resulted in the three other movement patterns and in large variations of the parameters, under the prevailing influence of individuals which masked the effect of other factors. TDT and AD are primarily influenced by the period (both are shorter in summer); AVR, DRP and FD are primarily influenced by sex (the daily range is greater in males).

\section{Behavioural aspects}

The meaning of activity zones and resting places: The present work is not aimed at interpreting the activities performed within the activity zones. We can only say that activity zones, as well as resting places, correspond to restricted areas where the individual spent a long time. Are these areas familiar, or selected along a random walk? If we make the null hypothesis that the activity zones are found at random, the average speed between zones, or between a zone and a resting place, should be similar to the average speed in absence of zone (strategy "ranging only"). We can consider 2 samples. First, the 8 sessions corresponding to the "ranging only" strategy. In this sample, we calculated the global average speed (TDT/AD). The second sample included the 23 sessions where connecting movements were observed, i.e. sessions containing at least one activity zone, with at least one of the resting places outside 
any activity zone. In this sample we calculated the average speed of slow and fast movements. The average speed in sample 2 was significantly greater than in sample 1 (respective means $0.827 \mathrm{~km} / \mathrm{h}$ and $0.494 \mathrm{~km} / \mathrm{h}, 29 d . f ., t=2.106, p=0.044$ ). This suggests that activity zones were not found at random.

Hierarchy of choices: The sequence of utilization of the supposedly "familiar" or "preferred" places (activity zones and resting places) and connecting movements can be expressed in terms of hierarchy of choices or decision making. A set of elementary decisions can be defined as follows:

(1) When the individual starts its active phase, 2 decisions are possible (initial decisions): begin zone activity here, or move away.

(2) When the individual is travelling away (en-route decisions): stop in a zone, or do not stop and reach the final resting place.

(3) When the individual is staying in a zone (within-zone decisions): stay until the resting phase starts, or move away.

The observed sequences of choice and the statistical tests are presented in Fig. 11. Let us analyze the choices with reference to the basic movement strategies. For the
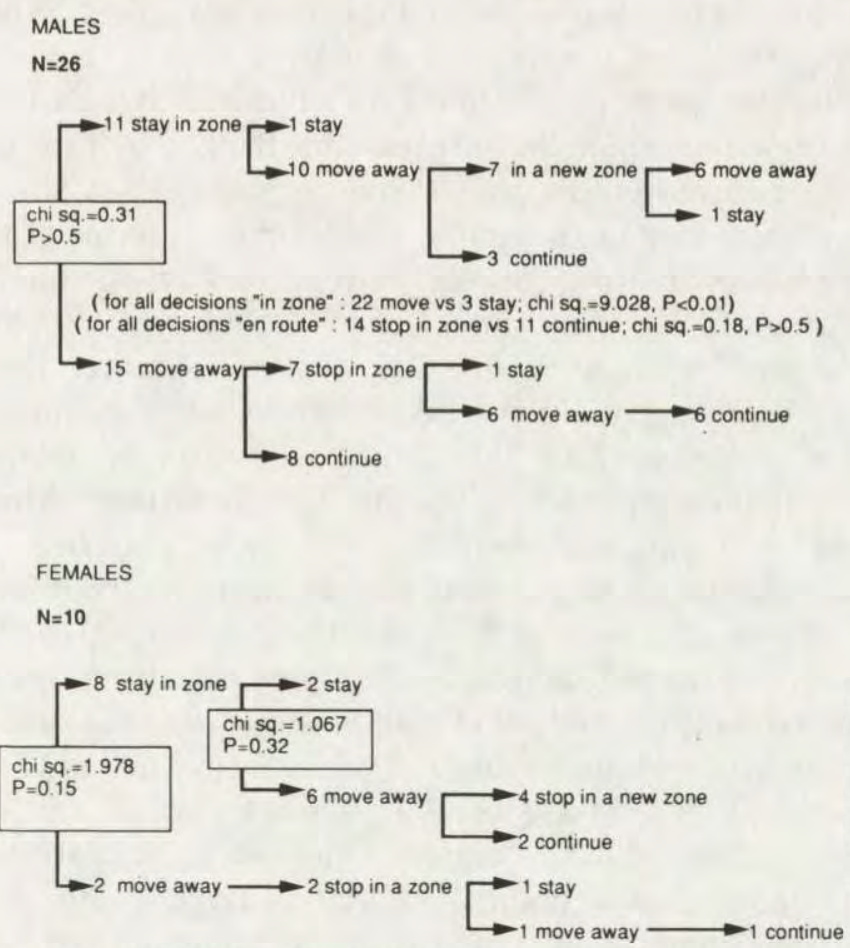

Fig. 11. Decision trees for male and female radio-tracking sessions. Test results are indicated on a pair of decisions in the case of simple pair comparison. Test results for cumulative comparisons are presented in the central part of the male graph. 
subadult males, there was no marked preference for one or the other strategies, neither initially (11 "staying in zone" vs 15 "moving away") nor after a first movement ( 7 vs 8 ). However, most males abandon their first activity zone (16 vs 2 ) even though the options "second zone" or "no second zone" are equally probable afterwards. Thus it is clear that males were able to use the "ranging only" strategy and that they tend to give up using the "staying in zone" strategy when they have initiated it. The observed females showed a marked preference for "staying in zone" both initially ( 8 vs 2 ) and after a first walk ( 2 vs 0 ). But similarly to the males they showed a tendency to abandon their first activity zone ( 7 vs 3 ). Breeding females therefore differed from males essentially because they did not use the "ranging only" strategy. But both categories exhibited the same tendency to leave their first activity zone before heading for their resting place.

\section{Discussion and conclusion}

A few authors have published comparable descriptions of the wild boar's daily movement. Three topics can be considered: the general classification of the movement, the distance parameters, and the time parameters.

Mauget (1980) proposed a classification of the daily active phase into two categories: in the first one, a long feeding period is flanked by two short movements. In the second, several movement phases and feeding periods succeed each other. This does not give any idea of the spatial pattern but, in terms of time budget, the first type can be assimilated to "simple" movements ("small zone" pattern, or an other pattern with a single activity zone) and the second type to "complex" patterns ("ranging" or "zigzag" or "loop" with 2 activity zones or more). However, the same activity zone may be used several times (with intermediate movement phases) so that some discrepancy appears between Mauget's classification and the patterns we have used. Other authors do not propose a classification in patterns. Most radiotracking maps in Douaud (1983) suggest "small zone" or "loop" patterns.

The total distance travelled was estimated by Mauget (1980) for more than 500 active phases concerning 7 females and 2 males. It averages 1,500 to $6,000 \mathrm{~m}$ according to sex, reproductive status and individual. Grouping data from Conley et al. (1972), Kurz and Marchinton (1972), Barrett (1978), Singer et al. (1981) and Douaud (1983) leads Janeau and Spitz to propose a range of values from 2,000 to $17,000 \mathrm{~m}$. However the mean values mentionned in these works are generally low (around $4,000 \mathrm{~m}$ ). TDT is generally longer for males than for females. Our results are characterized by a high diversity of TDT and it must be pointed out that an average value around $4,000 \mathrm{~m}$ is found in "small zone" and "loop" patterns, while "ranging" and "zigzag" averages more than $7,000 \mathrm{~m}$. This suggests that patterns similar to "small zone" and "loop" were more frequent than the other in the cited author's studies (Douaud 1983).

The same papers give a range of average durations from 8 to 11 hours, in contrast 
to our study where most activity durations fell between 10 and 16 hours. In most of the cited works, females appear to have a longer feeding activity than males, especially after farrowing. However a comparison between those different works is questionable on two points: Mauget $(1980,1984)$, Douaud (1983) and ourselves consider that activity begins with the first movement from the resting place and ends with the first fix recorded at the next resting place. Others (e.g. Singer et al. 1981) rely on the integrity of the signal to decide if the individual is resting or active. The second point concerns the onset of movement. In many cases, we have interpreted as "zone activity" small movements in the vicinity of the resting place that Mauget or Douaud would probably have considered as the final part of the resting phase. A better answer to that question was given by Janeau and Hachet (1988) by using activity sensors. They showed that the wild boar is active for $2 \%$ to $17 \%$ of the time spent at the resting place, and conversely that $4 \%$ to $20 \%$ of the time recorded as "active" by radio-tracking is devoted to rest (generally in activity zones). In the latter instance, rest occurs in short periods (less than half an hour). The same authors showed that the interpretation of "slow" activities as feeding activity is not always justified.

When considering other mammal species, it appears that spatial strategies comparable to what we found in wild boar, were observed in several carnivorous or omnivorous animals. Coyotes (Laundré and Keller 1981), lynx (Herrenschmidt et al. 1986), badgers (Kruuk 1978a and b, Sargeant and Warner 1982), polecat (Blanford 1987), and hedgehogs (Saboureau 1979, Kristiansson 1984) exhibit, similarly to wild boars, the use of small prey-searching areas away from the resting place, as well as long ranging movements between two successive resting places. Conversely to wild boar, however, predators frequently use a resting place just beside the last feeding area, and can re-use it for several days.

In conclusion, we can stress that all studies concerning the wild boar movements agree on the same basic results, i.e. the types of movement, the order of magnitude of the total distance covered, the time budget parameters, the main differences between males and females. Considering the fast connecting movements they usually perform, the wild boars seem to behave as if the areas they come accross were familiar, and as if activity zones were preferred areas. But the latter point would need confirmation by recording several successive 24 -hour periods of the same individuals. Regular re-using of the same activity zone has been proved only under enclosed conditions (Mauget 1980 ) or in cultivated areas where favourable habitats are scarce (Spitz and Pépin 1985).

One of the major points concerns the relation between activity zones and resting places. The tendency to abandon the first activity zone is observed in both sexes, including females with piglets for which the only movement outside the zone is aimed at reaching a distant resting place. This behaviour could be interpreted as antipredatory: an attempt at placing the bed far from an area where the individual left a lot of signs. It could also be interpreted in terms of social relationship. If we refer to Mauget (1980) and Altmann (1985) the wild boars tend to be territorial during the 
rest phase. We can suppose that a group of individuals present in an activity zone disperse from it to reach separate beds.

The present work proposes the hypothesis that two basic strategies can be used singly or in combination by wild boar, and that the way wild boar use these strategies result in the observed pattern of movement. On the other hand, the quantitative parameters of the daily range depend, by order of priority, on individual, sex and time of the year. Some questions stay unanswered: is the continuous use of "ranging only" possible? Do other movement patterns exist in the same population or in other?

Finally, every interpretation of these movement data in terms of activity is questionable without specific activity recording. However the gross distinction of "possibly feeding" (with two movement types: slow movement and activity zones) versus "non-feeding" (fast movement) leads to interesting results concerning the hierarchy of choices, which could be very useful when relating movement results to habitats and resources.

Acknowledgements: We are grateful to the radio-tracking team in Grésigne: E. Lécrivain and G. Valet, and all other (our Polish friends R. Matuszewski and R. Dzieciołowski included!) who helped us in various ways. Thanks to P. Duncan for examining this manuscript at diverse stages. All the field work was feasible thanks to the cooperation of the Office National des Forets, Toulouse and Castres, France.

\section{References}

Altmann D. 1985. Temporal diffrences in social, agonistic and territorial behaviour of Sus scrofa. IVth Int. Theriol. Congr., Edmonton, Canada (abstract only).

Baettig M. 1980. Premiére étude sur les déplacements des sangliers en Suisse romande. Diana 97: 228 - 231.

Barrett R. H. 1978. The feral hog of the Dye Creek Ranch. Hilgardia 46: $283-355$.

Blanford P. R. S. 1987. Biology of the polecat Mustela putorius: a literature review. Mamm. Rev. 17: 155-198.

Calhoun J. B. and Casby J. U. 1958. Calculation of home range and density of small mammals. U.S Public Health Service. Public Health Monographs 55: 1-24.

Conley R. A., Henry V. G. and Matschke G. H. 1972. Final Report for the European wild hog research project W34 R.5. Tenn. Wild. Resour. Agency: 1-259.

Dietrich U, 1984. Ergebnisse und Tendenzen der Forschungen am Wildschwein Sus scrofa in den Jahren 1975-1983. Säugetierk. Mitt. 31: 223-237.

Douaud J. F. 1983. Utilisation de l'espace et du temps et ses facteurs de modulation chez le sanglier, Sus scrofa L., en milieu forestier ouvert (Massif des Dhuits, Haute-Marne). Thése 3éme cycle, Univ. Strasbourg: X + 1-149 pp.

Gundlach H. 1968. Brutfürsorge, Brutpflege, Verhaltenontogenese und Tagesperiodik beim Europäischen Wildschwein. Z. für Tierpsychol. 25: 955-995.

Heezen K. L. and Tester J. R. 1967. Evaluation of radiotracking by triangulation with special reference to deer movement. J. Wildl. Manage. 31: 124-141.

Herrenschmidt V., Léger F. and Terrier G. 1986. Mode d'occupation spatiale des lynx (Felix lynx L.) introduits dans le massif vosgien. Premiers résultats. Gibier Faune Sauvage 3: 67-81.

Janeau G. and Hachet T. 1988. Utilisation de la biotélémétrie pour l'étude de l'activité des animaux sauvages. Int. Coll. Radiotelem. for tracking terrestrial vert. (in print). 
Janeau G. and Spitz F. 1984. L'espace chez le sanglier: occupation et mode d'utilisation journaliére. Gibier Faune Sauvage 1: $73-89$.

Kristiansson H. 1984. Ecology of a hedgehog (Erinaceus europaeus) population in southern Sweden. Dissert. Univ. Lund.

Kruuk H. 1978a. Foraging and spatial organization of the European badger, Meles meles L. Behav. Ecol. Sociobiol. 4: $75-89$.

Kruuk H. 1978b. Spatial organization and territorial behaviour of the European badger, Meles meles. J. Zool., Lond. 184: 1-19.

Kurz J. C. and Marchinton R. L. 1972. Radiotelemetry studies of feral hogs in South Carolina. J. Wildl. Manage. 36: $1240-1248$.

Laundré J. W. and Keller B. L. 1981. Home range use by coyotes in Idaho. Animal Behav. 29: 449-461.

Mauget R. 1979. Mise en évidence, par captures-recaptures et radiotracking, du domaine vital chez le sanglier (Sus scrofa L.) en forét de Chizé. Biol. Behav. 1: 25-41.

Mauget R. 1980. Régulations écologiques, comportementales et physiologiques (fonction de reproduction) de l'adaptation du sanglier (Sus scrofa L.) au milieu. Thése de Doctorat d'Etat Univ. Tours: 1-295.

Mauget R. 1984. Rythme d'activité et budget-temps chez le sanglier européen (Sus scrofa L.). Coll. INRA 22:79-92.

Mauget R., Campan R., Spitz F., Dardaillon M., Janeau G. and Pépin D. 1984. Synthése des connaissances actuelles sur la biologie du sanglier, perspectives de recherche. Coll. INRA 22: 15-50.

Mauget R. and Sempéré A. 1978. Comportement locomoteur déterminé par radiotracking chez deux ongulés sauvages en liberté: le chevreuil (Capreolus capreolus L.) et le sanglier (Sus scrofa L.). Biol. Behav. 3: $331-340$.

Morgan J. N. and Sonquist J. R. 1963. Problems of the analysis of survey data. J. Am. Stat. Ass. 58: $415-434$.

Pépin D., Spitz F., Janeau G. and Valet G. 1987. Dynamics of reproduction and development of weight in the wild boar (Sus scrofa) in south-west France. Z. Säugetierk. 52: 21-30.

Saboureau M. 1979. Cycle annuel du fonctionnement testiculaire du hérisson (Erinaceus europaeus). Sa régulation par les facteurs externes et internes. $\mathrm{Ph}$. D. thesis, d'Etat Univ. Tours.

Sargeant A. B. and Warner D. W. 1972. Movements and denning habits of a badger. J. Mammal. 53: $207-210$.

Singer F. J., Otto D. K., Tipton A. R. and Hable C. P. 1981. Home ranges, movements and habitat use of European wild boar in Tenessee. J. Wildl. Manage. 45: 343-353.

Spitz F. 1984. Démographie du sanglier en Grésigne (sud-ouest de la France) Coll. INRA 22: 151-157.

Spitz F. 1989. Modelling animal movement recorded by radiotracking. [In: Biotelemetry. C. J. Amlaner, ed.] University of Arkansas Press, Fayetteville: $685-694$.

Spitz F., Janeau G, and Valet G. 1984. Eléments de démographie du sanglier (Sus scrofa) dans la région de Grésigne. Oecol. applic. 5: 43-59.

Spitz F. and Pépin D. 1985. Occupation de l'espace par le sanglier en zone de grande culture. Trans. XVIIth congress IUGB. Minist. Agric. Belgique (édit): 953-959.

Tester J. R. and Siniff D. B. 1965. Aspects of animal movements and home range data obtained by telemetry. Trans. N. Am. Wildl. and Nat. Res. Conf. 18: 379-392.

Received 15 July 1989, accepted 25 January 1990. 